\title{
Experimental induction of resins as a tool to understand variability in ambers
}

\author{
Leyla J. Seyfullah ${ }^{1,2}$, Emily A. Roberts ${ }^{1,3}$, Phillip E. Jardine ${ }^{4}$, and Alexander R. Schmidt ${ }^{2}$ \\ ${ }^{1}$ Department of Palaeontology, University of Vienna, 1090 Vienna, Austria \\ ${ }^{2}$ Department of Geobiology, University of Göttingen, 37077 Göttingen, Germany \\ ${ }^{3}$ School of Earth and Environmental Sciences, University of Portsmouth, Portsmouth, PO1 3QL, UK \\ ${ }^{4}$ Institute of Geology and Palaeontology, University of Münster, 48149 Münster, Germany
}

Correspondence: Leyla J. Seyfullah (leyla.seyfullah@univie.ac.at)

Received: 19 July 2021 - Revised: 6 September 2021 - Accepted: 7 September 2021 - Published: 11 October 2021

\begin{abstract}
Amber is chiefly known as a preservational medium of biological inclusions, but it is itself a chemofossil, comprised of fossilised plant resin. The chemistry of today's resins has been long investigated as a means of understanding the botanical sources of ambers. However, little is known about the chemical variability of resins and consequently about that of the ambers that are derived from particular resins. We undertook experimental resin production in Araucariacean plants to clarify how much natural resin variability is present in two species, Agathis australis and Wollemia nobilis, and whether different resin exudation stimuli types can be chemically identified and differentiated. The latter were tested on the plants, and the resin exudates were collected and investigated with Fourier-transform infrared attenuated total reflection (FTIR-ATR) spectroscopy to give an overview of their chemistry for comparisons, including multivariate analyses. The Araucariacean resins tested did not show distinct chemical signatures linked to a particular resininducing treatment. Nonetheless, we did detect two separate groupings of the treatments for Agathis, in which the branch removal treatment and mimicked insect-boring treatmentderived resin spectra were more different from the resin spectra derived from other treatments. This appears linked to the lower resin viscosities observed in the branch- and insecttreatment-derived resins. However the resins, no matter the treatment, could be distinguished from both species. The effect of genetic variation was also considered using the same stimuli on both the seed-grown A. australis derived from wild-collected populations and on clonally derived $W$. nobilis plants with natural minimal genetic diversity. The variability in the resin chemistries collected did reflect the genetic vari-
\end{abstract}

ability of the source plant. We suggest that this natural variability needs to be taken into account when testing resin and amber chemistries in the future.

\section{Introduction}

Amber (fossilised plant resin) is well known for its fine preservation of organisms (biological inclusions), often even facilitating the preservation of tissues (Henwood, 1992; Grimaldi et al., 1994). Excellent preservation of inclusions has even allowed carotenoid pigments (Thomas et al., 2014) and amino acids (McCoy et al., 2019) to be recovered. There is some evidence that resin chemistry may partly affect whether an entrapped organism becomes fossilised and the quality of its subsequent preservation (McCoy et al., 2017a).

Amber itself is a chemofossil, a polymerised resin that has undergone further chemical alteration through the maturation process after burial in sediments (Ragazzi and Schmidt, 2011). A question of increasing importance is then what potential chemical information that originated from the plant at the time of resin exudation could be stored in this preserved resin. Numerous studies are exploring the isotopic and wider chemical properties of different ambers to examine these potentially fossilised chemical signals.

The chemical stability of ambers is useful for investigating carbon isotopes as the amber chemistry is not greatly altered by maturation (Nissenbaum and Yakir, 1995; Stout, 1995; Aquilina et al., 2013; Dal Corso et al., 2013, 2017). The carbon isotopic values of ambers have been used to infer palaeoenvironmental conditions surrounding the resinous 
source plants at the time of exudation (e.g. Nissenbaum et al., 2005; Gaigalas and Halas, 2009; Aquilina et al., 2013; Dal Corso et al., 2017). McKellar et al. (2011) suggested that insect-damage-induced resin exudation may produce carbon isotopic markers and may be traceable in ambers. However, Dal Corso et al. (2017) showed that the carbon isotopic value of exuded resins in modern plants can vary even in one tree depending on height along the main trunk. They also showed that different species in different genera growing at the same locality can vary in their carbon isotopic compositions (up to $6 \%$ ) and that increasing altitude causes the ${ }^{13} \mathrm{C}$ enrichment of exuded resins (Dal Corso et al., 2017). This shows that investigating modern resins as analogues for amber in the fossil record is complex and needs more thorough investigation.

Others have searched for biomarker chemicals contained in the amber itself, such as distinctive chemicals that can indicate the amber source plant to genus level (e.g. Otto et al., 2002; Yamamoto et al., 2006; Pereira et al., 2009; McCoy et al., 2017b). Currently, there are little data available on resin chemistry variability when exuded in response to differing stimuli. It is thought that abiotic factors, such as light, temperature, moisture stress, and soil nutrients, have no effect on resin chemistry, although biotic factors such as herbivory may have effects (Langenheim, 1990; Dutta et al., 2017; McCoy et al., 2017b). This opens a possible path to examining a major question surrounding amber deposits: why the original resin was exuded and sometimes in vast amounts. Many different reasons for resinous outpouring have been suggested (summarised in Seyfullah et al., 2018a) with the key ideas for resin production in the fossil record being as follows: heightened fire incidence (e.g. Grimaldi et al., 2000; Najarro et al., 2010), climate change (e.g. Rust et al., 2010; Seyfullah et al., 2018b), local environmental scale damage, e.g. hurricane damage (e.g. Grimaldi, 1996), and the evolution of new wood-boring insect groups (e.g. Grimaldi et al., 2000).

A key research priority is therefore to understand how the chemical signature of plant resins relates to different production stimuli, and whether this information is obtainable from amber in the fossil record. Here we report a set of actuopalaeontological experiments designed to stimulate resin exudation in response to different stimuli to understand its variability both within species and between two species in the same family. The likely effect of genetic variation on resin chemistry variation is also examined. Fourier-transform infrared attenuated total reflection (FTIR-ATR) spectroscopy analysis was used as it is efficient, non-destructive, and regularly used to profile ambers and resins (e.g. Tappert et al., 2011; Seyfullah et al., 2015; Wolfe et al., 2016).

\section{Materials and methods}

\subsection{Resinous plants used}

Two species of the Araucariaceae Henkel \& W. Hochstetter were used for the experiments: Agathis australis (D. Don) Loudon and Wollemia nobilis W. G. Jones, K. D. Hill \& J. M. Allen. Today, A. australis is found in northern New Zealand and is considered to be the source plant for many New Zealand subfossil resins (copals) and ambers (Lambert et al., 1993; Lyons et al., 2009; Seyfullah et al., 2015; Schmidt et al., 2018), rendering it an ideal choice for investigating the link between resins and ambers. The A. australis plants were seed-grown trees, reflecting their natural genetic - and so potential resin - variation, enabling us to assess any natural resin chemistry variability, although Tappert et al. (2011) showed intraspecific resin chemistry variation to be much lower than interspecific variation. Due to importation/exportation limitations of plant materials, the experiments on A. australis were carried out in New Zealand on this species.

The natural relict Wollemia population has a very low genetic diversity (Peakall et al., 2003; Greenfield et al., 2016) and has been clonally increased, so all plants should react as though they are mature, which makes these clones ideal test subjects. All the Wollemia trees used were branch clones of older branch clones provided to European nurseries and shipped to Germany. Wollemia nobilis trees were used for the experiments as these are the most resinous Araucariaceans available in Europe. Comparing resin variability between the two species allowed us to assess the effect of within-population genetic variability on resin chemistry, as well as assessing the relative contributions of stimulus type and botanical affinity.

\subsection{Treatment set-up in New Zealand (Agathis australis)}

The Agathis australis were all 10-year-old seed-sown plants (Fig. 1a) grown at Oratia Plant Nursery, West Coast Road, Glen Eden, Auckland ( $\left.36^{\circ} 54^{\prime} 52^{\prime \prime} \mathrm{S}, 174^{\circ} 36^{\prime} 50^{\prime \prime} \mathrm{E}\right)$. The plants were grown within their zone of natural occurrence in New Zealand (from Steward and Beveridge, 2010; here Fig. 1b). Of the 80 available trees, 20 were rejected as they looked unhealthy or were very different in height or appearance from the remaining plants. The selected 60 plants were then placed into groupings of 10 across a plot in the nursery for the treatment and observations. A total of 10 trees per treatment were used, with 5 treatments in total, plus 10 as control plants. All the treatments started on day 1. The treatments are analogous variants of physical damage that wild plants might be subjected to naturally and are thought to trigger resin exudation. The treatments were as follows: (1, “cutoff", Fig. 2a) cutting plants down to $20 \mathrm{~cm}$ from the soil surface to mimic catastrophic damage; (2, "insect", Fig. 2c) 
boring ten $1 \mathrm{~mm}$ holes $10 \mathrm{~mm}$ deep into the top $20 \%$ of the trunks to mimic insect borings; (3, "branch", Fig. 3a) removing three upper branches from the trunks to mimic abrupt but not catastrophic physical damage; (4, "burn", Fig. 3c) in which the trunk was burned on one side for 1 min with a blow torch held $10 \mathrm{~cm}$ away at around $20 \mathrm{~cm}$ from the soil surface, creating a burn $4-6 \mathrm{~cm}$ in length along the trunk to mimic a wild fire burning at a low level; (5, "leaf-fire") in which the upper part of the plant/canopy was subjected to burning, plus a control group which was not subject to any treatments.

\subsection{Treatment set-up in Germany (Wollemia nobilis)}

Due to the rampant fatal Phytophthora infection of many specimens and clonal source plants across Europe (and worldwide), far fewer trees were available for these treatments than planned. In total 24 trees were sourced and grown in the glasshouses at the Experimental Botanical Garden of the University of Göttingen $\left(51^{\circ} 33^{\prime} 22^{\prime \prime} \mathrm{N}, 9^{\circ} 57^{\prime} 18^{\prime \prime} \mathrm{E}\right)$. These trees were more variable in their age, size, and maturity than the A. australis specimens (Fig. 4). The trees were grown together for a year after immediate repotting to impose similar growth conditions on the test trees. The resinous polar caps of the trees, except for those on the controls, were ignored as these are produced seasonally to protect the developing apices of the plants from the cold (Royal Botanic Garden Sydney, https://www.rbgsyd.nsw. gov.au/Plants/Gardening/Growing-Wollemi-Pines-1, last access: 2 May 2021). After this, seven treatments and a control group, each with three plants, were created. A range of sizes and maturities were selected for each group. All the treatments started on day 1.

The treatments were again analogous variants of physical damage that wild plants might be subjected to naturally and are thought to trigger resin exudation. The treatments were as follows: (1, "cutoff", Fig. 5a) cutting plants down to $20 \mathrm{~cm}$ from the soil surface to mimic catastrophic damage (same as the Agathis tests); (2, "insect", Fig. 5c) boring ten $1 \mathrm{~mm}$ holes $10 \mathrm{~mm}$ deep into the top $20 \%$ of the trunks to mimic insect borings (same as the Agathis tests); (3, "branch", Fig. 6a) removing three upper branches from the trunks to mimic abrupt but not catastrophic physical damage (same as the Agathis tests); (4, "burn", Fig. 6c) in which the trunk was burned on one side for $1 \mathrm{~min}$ with a blow torch held $10 \mathrm{~cm}$ away at around $20 \mathrm{~cm}$ from the soil surface, creating a burn $4-6 \mathrm{~cm}$ in length along the trunk to mimic a wild fire burning at a low level (same as the Agathis tests); (5, "flood") in which trees were placed in individual troughs of water to mimic flooding events for which the water level was high $(5 \mathrm{~cm}$ from the top of the pots) for 1 week and was gradually lowered throughout the several weeks of the experiment; (6, "drought") in which the watering regime was halved for these trees compared to all others to mimic times of water stress; (7, "flood + insect") in which the trees were subjected to two simultaneous treatments: they were placed in individual troughs of water to mimic flooding events, again the water level was high $(5 \mathrm{~cm}$ from the top of the pots) for 1 week and gradually lowered throughout the experiment, and ten $1 \mathrm{~mm}$ holes $10 \mathrm{~mm}$ deep were bored into the top $20 \%$ of each trunk to mimic insect borings. These last three treatments are not figured as they yielded only tiny amounts of resin.

\subsection{Observation and collection of resins}

For both experimental set-ups, each plant was numbered, observed, and photographed prior to the experiment. Resins exuded by each plant were observed and photographed each morning for $21 \mathrm{~d}$. This was when the resin exudation had clearly stopped for all treatments, and no further fresh resin had been produced for several days; then the exuded resins were collected. This was done by using individual sterile scalpels to scrape the resins from the tree into stoppered tubes whilst being careful not to incorporate any bark into the resins to minimise contamination. Not all plants produced resins, and the quantities of resin exuded varied. For the $A$. australis treatments, there are 30 separate resin samples in total in the analyses. A total of 10 samples are from the branch treatment trees, 8 from both the cutoff and insect treatment trees, and 4 from the burn treatment trees. The control trees produced no resin during the observation period. The leaffire treatment produced so little resin that it could not be used for any analyses. For the $W$. nobilis treatments, there are 22 separate resin samples in the analyses: two each came from the drought and fire treatments, three each from the cutoff and flood + insect treatments, four from the branch treatment (here tree 2 gave no resin, one sample was from tree 1, and three came from tree 3 - one from each branch removal site as so much resin was exuded and to test whether there was any difference in their chemistries), and six from the insect treatment (four samples came from tree 1 as there was so much resin and to see if the height of the damage made any difference to the resin chemistry, with only one sample each from the other trees). The control trees produced no resin during the observation period, but two polar cap exudates were collected for comparison. The flood treatment did not yield enough resin for testing. The resins had mostly already hardened all the way through on the trees at time of collection, which was noted at time of collection for each sample. The hardened resins were white and cloudy compared with the more translucent, less hardened resins. The resins were then left for 3 months in their collection tubes for any further loss of volatiles or hardening to occur.

\subsection{FTIR spectroscopy}

The resins were examined under a binocular microscope to check for any contaminants. Uncontaminated and hardened resin pieces (any potentially softer looking, more translucent pieces were removed to limit any measurement of possible volatiles from pieces of resin that were not fully hard- 

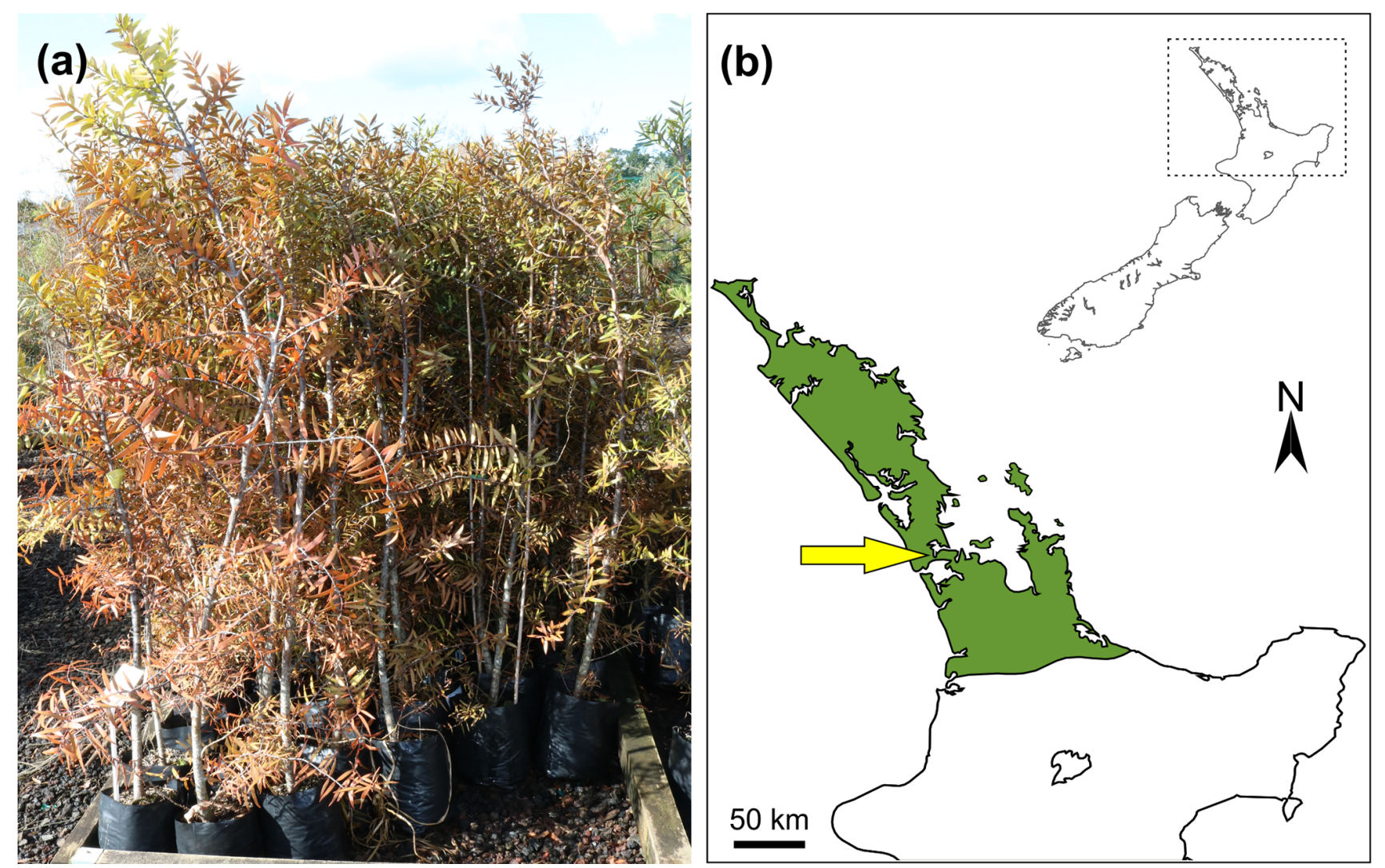

Figure 1. Agathis australis grown in New Zealand: (a) seed-grown 10-year-old Agathis australis trees at Oratia Plant Nursery before the start of the experiment; (b) map of New Zealand (inset) with dashed rectangle indicating area of interest. Enlarged area shows the natural range (in green) of the endemic Agathis australis in New Zealand, based on Steward and Beveridge (2010); site of experiment at Oratia is arrowed.

ened) were then selected and individually powdered to avoid cross-contamination, with extensive cleaning between sample preparations. The powdered resins were then analysed using FTIR spectroscopy (Bruker Vertex 70) using a Globar light source, a KBr beamsplitter, and a DLaTGS detector. The spectrometer was constantly purged by dry air to reduce background signals from atmospheric $\mathrm{H}_{2} \mathrm{O}$ and $\mathrm{CO}_{2}$. The spectra were collected in attenuated total reflection (ATR) mode using a Bruker Platinum A225 diamond ATR accessory that was installed in the sample chamber of the spectrometer. The powdered sample was placed on the $2 \times 2 \mathrm{~mm}$ surface of the diamond and was pressed onto the crystal by a torque-controlled anvil. For each sample spectra were collected in the range from 4000 to $650 \mathrm{~cm}^{-1}$ in 32 scans with a spectral resolution of $4 \mathrm{~cm}^{-1}$. A background spectrum was taken before each sample spectrum. Each sample was measured three times to ensure consistency, with one spectrum per sample chosen for further analysis. The ATR crystal and anvil were cleaned thoroughly with ethanol between samples to prevent cross-contamination. The spectra were visualised using SpectraGryph v1.2.13, and absorption bands were identified by comparison with previous reports (Lyons et al., 2009; Tappert et al., 2011; Beltran et al., 2016).

\subsection{Statistical analyses using $R$}

All data manipulation and analysis were carried out in $\mathrm{R}$ version 4.1.0 (R Core Team, 2021) with the packages baseline version 1.3-1 (Liland et al., 2010) and RColorBrewer version 1.1-2 (Neuwirth, 2014) (see Supplement). Each spectrum was standardised to zero mean and unit variance ( $z$ scores) using the equation $(x-\bar{x}) / \sigma$, where $x$ is the absorbance value, $\bar{x}$ is the spectrum arithmetic mean, and $\sigma$ is the spectrum standard deviation. The baseline was corrected using modified polynomial fitting, with a second order polynomial baseline (Liland et al., 2010). We used principal component analysis (PCA) and cluster analysis for data visualisation and exploration (Varmuza and Filzmoser, 2009). The PCA and cluster analyses were run on the sample spectra. The cluster analysis was run using the Euclidean distance and with the unweighted pair group method with arithmetic mean (UPGMA) linkage algorithm. The two experimental datasets were analysed both separately and combined together using these methods (see Supplement). 

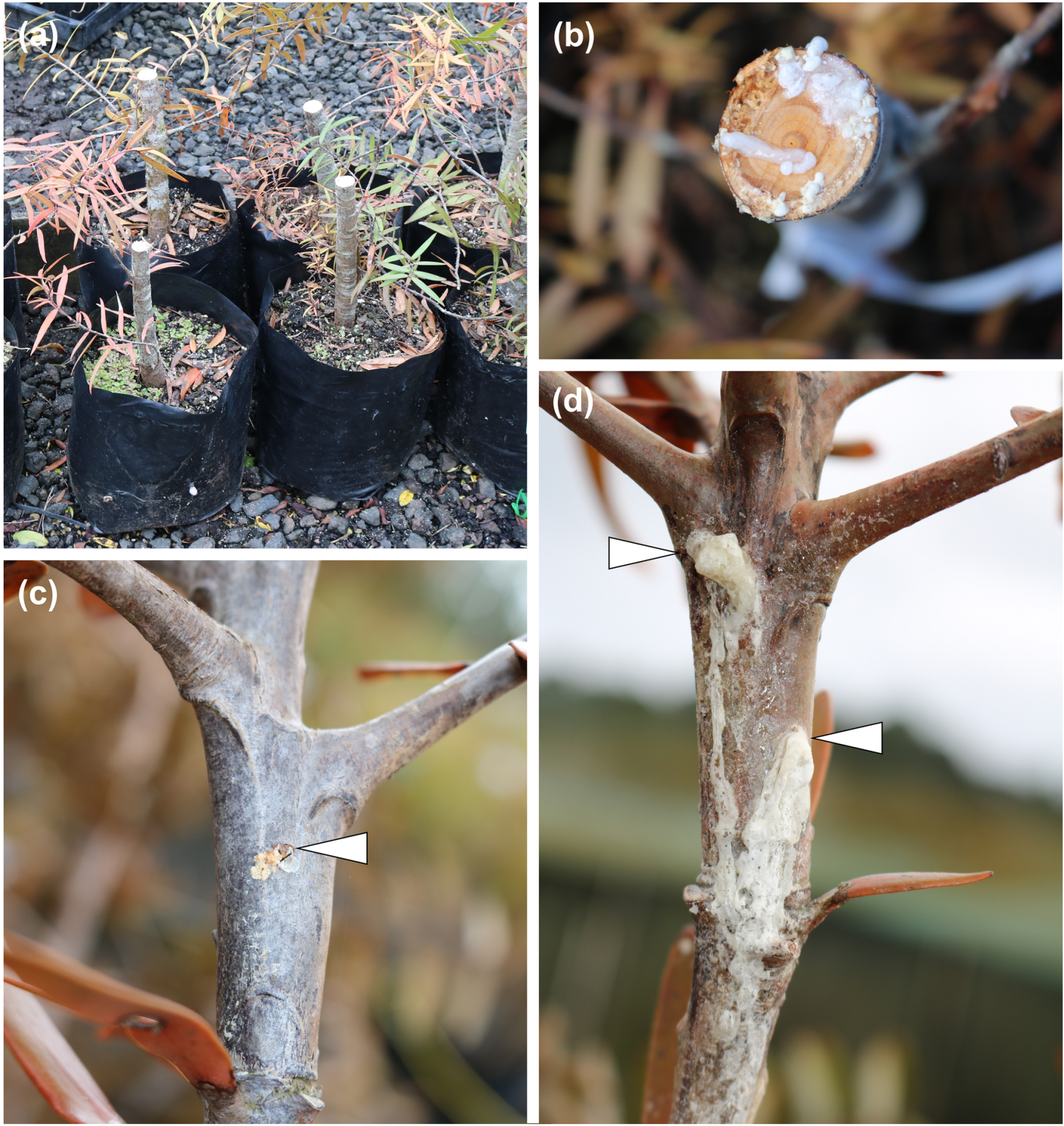

Figure 2. Experimental Agathis australis examples: (a-b) cutoff treatment in which the trees were cut at $20 \mathrm{~cm}$ above soil level to mimic catastrophic damage; (c-d) insect treatment in which holes were drilled into the top $20 \%$ of the trunks to mimic wood-boring insect attack; (a) day 1 of cutoff treatment; (b) final day of cutoff treatment with viscous white resin visible; (c) day 1 of the insect treatment with one drilled hole visible (arrowhead); (d) final day of insect treatment in which two drill holes have exuded less viscous white resin (arrowheads). 

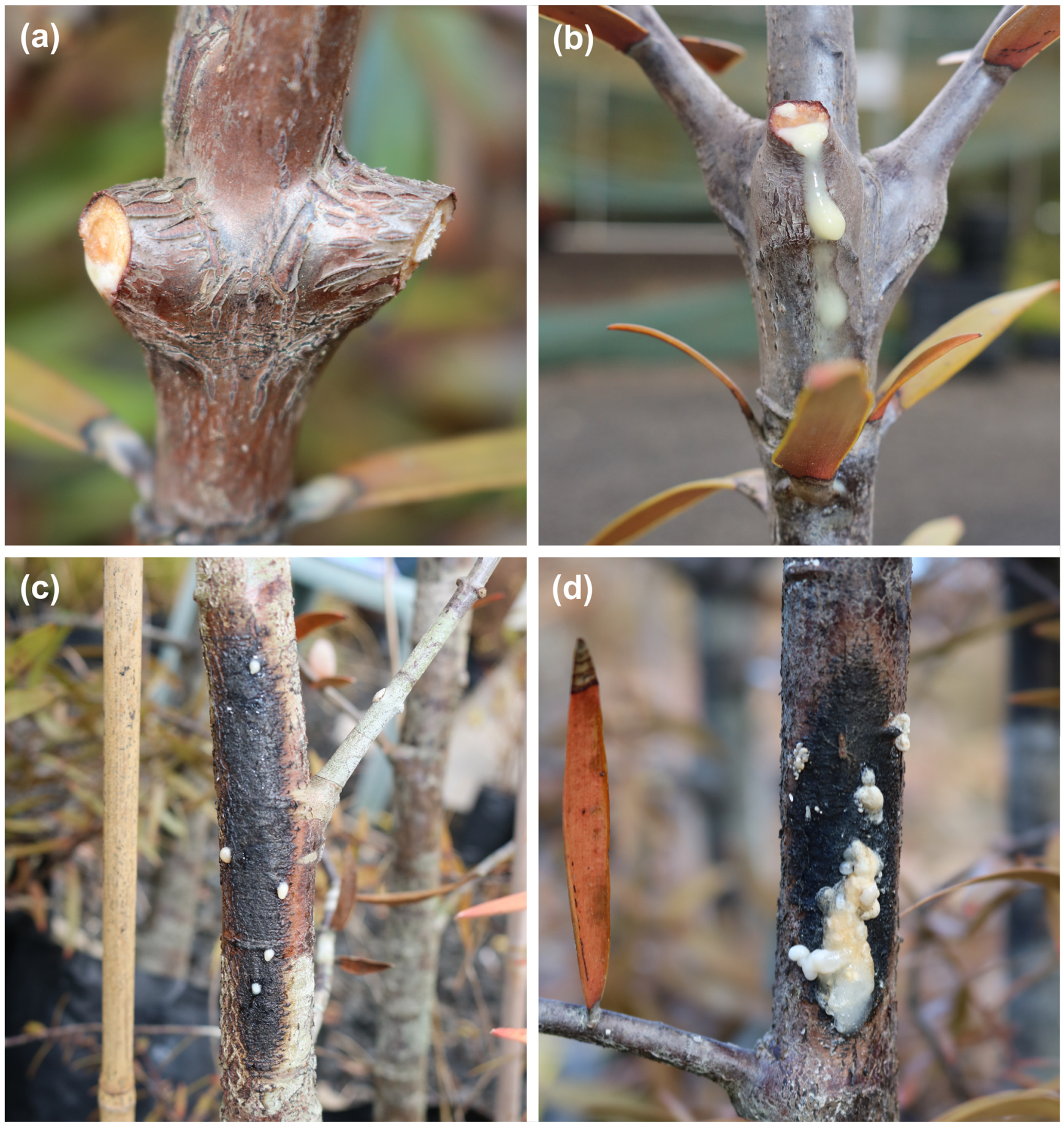

Figure 3. Experimental Agathis australis examples: (a-b) branch treatment in which three upper branches were removed to mimic noncatastrophic damage; (c-d) burn treatment in which each tree was burned on one side creating a burn $6 \mathrm{~cm}$ in length along the trunk to mimic a wild fire burning at a low level; (a) day 1 of branch treatment; (b) final day of branch treatment with less viscous light yellow resin visible; (c) day 1 of the burn treatment with small resin beads forming; (d) final day of burn treatment with viscous exudation. 


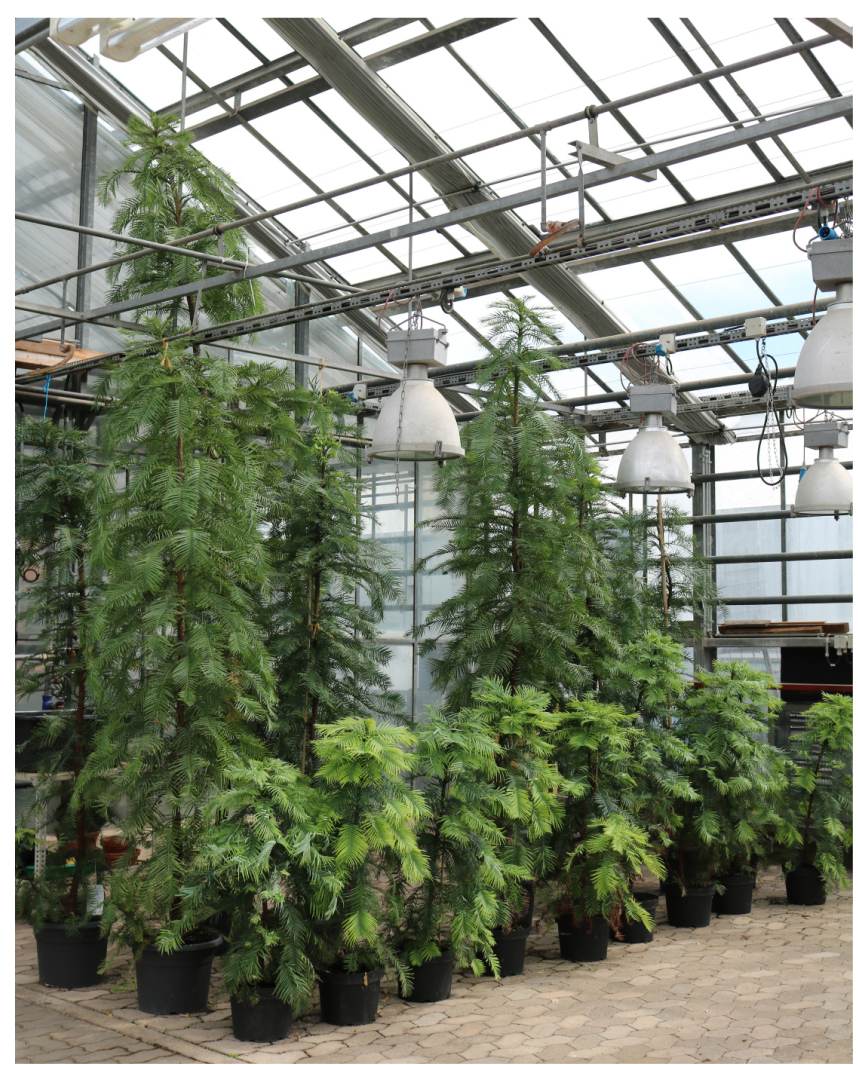

Figure 4. Variation in tree sizes seen in the Wollemia nobilis clonal plants available and grown together in Göttingen prior to experimentation (tallest tree $2.4 \mathrm{~m}$ in height).

\section{Results}

\subsection{Agathis resin exudation experiment}

The control trees were found to produce no resin during the observation period. The leaf-fire treatment produced so little resin that it could not be used for any analyses. The four remaining treatments did produce resin in the plants, and the amounts varied between treatments and also between trees within each treatment group. A total of 30 separate resin samples were collected, 10 from the branch treatment trees, 8 from both the cutoff and insect treatment trees, and 4 from the burn treatment trees. Of these, the least amount of resin was produced by the cutoff treatment trees (Fig. 2b), followed by the branch treatment trees (Fig. 3b) in contrast to the insect treatment trees (Fig. 2d) and the burn treatment trees (Fig. 3d), which produced the most resin. The least viscous resin that ran further down the trees was generally observed in some of the insect and branch treatment trees (Figs. 2d, 3b) but not all and not at every injury site on the same tree. The most viscous resins (in which the resin did not drip so far down the trees) were mainly exuded in response to the cutoff and all burn treatments (Figs. 2b, 3d).
The FTIR spectra of Agathis australis resins show the peaks diagnostic for all resins (Fig. 7a). The wide $3400 \mathrm{~cm}^{-1}$ peak is linked to stretching of $\mathrm{O}-\mathrm{H}$ bonds and the small peak at $3076 \mathrm{~cm}^{-1}$ due to $\mathrm{C}-\mathrm{H}$ stretching of monoalkyl groups, whereas the dominant peak at $2935 \mathrm{~cm}^{-1}$ and the small peak at $2848 \mathrm{~cm}^{-1}$ are associated with methylene groups. The small peak at $2870 \mathrm{~cm}^{-1}$ is related to methyl groups, and the large peak at $1693 \mathrm{~cm}^{-1}$ with a peak on the shoulder at $1722 \mathrm{~cm}^{-1}$ is due to $\mathrm{C}-\mathrm{O}$ double bonds in carboxyl groups of resin acids (Tappert et al., 2011; Seyfullah et al., 2015). Below this is the fingerprint region, which is highly variable between different resins. In Agathis the peaks at 1448 and $1385 \mathrm{~cm}^{-1}$ are due to $\mathrm{C}-\mathrm{H}$ bending motions of methyl and methylene functional groups, the peak at $1234 \mathrm{~cm}^{-1}$ is assigned to $\mathrm{C}-\mathrm{O}$ single bonds, and the large peak at $887 \mathrm{~cm}^{-1}$ is due to the out-of-plane $\mathrm{C}-\mathrm{H}$ bending motions in terminal methylene groups (Tappert et al., 2011). The mean FTIR spectra for the treatments demonstrate clear differences in the fingerprint region (the region below $1800 \mathrm{~cm}^{-1}$ ), with the most striking observation being the peak differences between 1288 and $1098 \mathrm{~cm}^{-1}$ (see Fig. 7b area between dashed lines). In the insect and branch treatments there is a larger single peak at $1229 \mathrm{~cm}^{-1}$. This peak is followed by a smaller doublet at 1174 and $1150 \mathrm{~cm}^{-1}$. In contrast the cutoff and burn treatment resins show a less intense peak at $1235 \mathrm{~cm}^{-1}$ with a shoulder at $1259 \mathrm{~cm}^{-1}$ that is more similar in intensity to the doublet at 1174 and $1150 \mathrm{~cm}^{-1}$. The peak or first doublet results from $\mathrm{C}-\mathrm{O}$ single bonds, $\mathrm{C}-\mathrm{C}-\mathrm{O}$ stretching, and $\mathrm{O}-\mathrm{H}$ deformation in $-\mathrm{COOH}$ groups, and the second doublet relates to $\mathrm{C}-\mathrm{O}$ single bonds in the resins (Beltran et al., 2016; Lyons et al., 2009; Tappert et al., 2011).

For this Agathis experiment, more than $94 \%$ of the variance was accounted for by two principal components (percentage of variance for PC1: 84.59\%; PC2: 9.86\%; standard deviation for PC1: 7.37; PC2: 2.52), so no further principal components were needed to describe the variation. In terms of the resin chemistry produced from each tree in each treatment group, each treatment clusters together (Fig. 8a), but there are overlaps between the treatments and a potential arch effect on PC1, which shows a gradient from cutoff to burn to insect to branch treatment resin spectra. The PC1 loadings for Agathis shows that the peaks at 1229, 1693, and $1722 \mathrm{~cm}^{-1}$, identified above, are key to the spectral differences in the Agathis treatments (Fig. 8b). A similar result to the PCA is also seen in the cluster analysis (Fig. 8c), in which the treatments can be divided, more or less, into two main clusters, one containing all the cutoff treatment trees and all but one burn tree. The other cluster comprises all the insect and branch treatment trees, plus one burn tree. The one burn tree resin that clusters towards the insect and branch treatments had a less viscous resin more similar to that observed being exuded in the insect and branch treatment trees rather than the more viscous resin exuded in response to the cutoff and other burn treatments. 

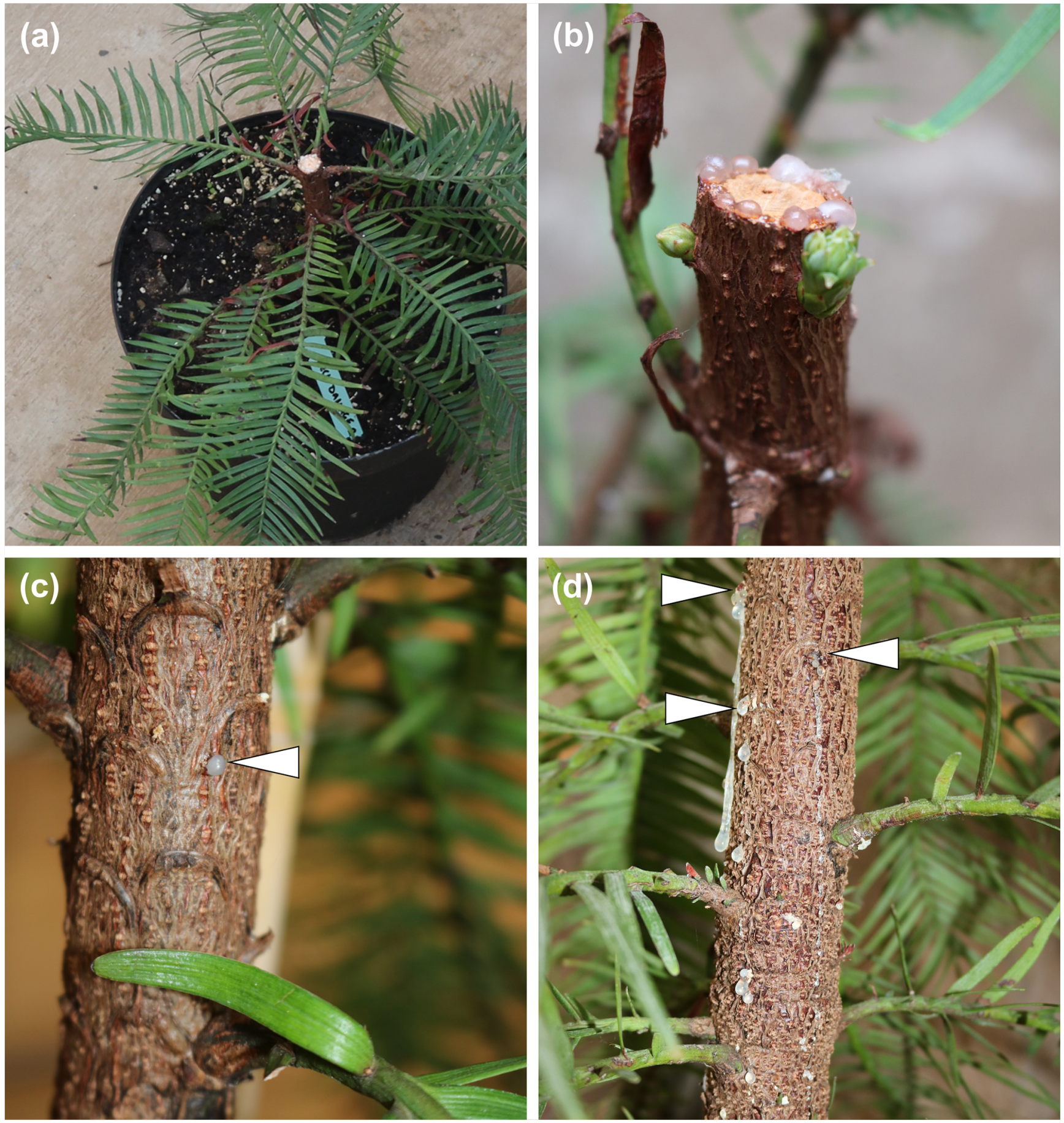

Figure 5. Experimental Wollemia nobilis examples: (a-b) cutoff treatment in which the trees were cut at $20 \mathrm{~cm}$ above soil level to mimic catastrophic damage; (c-d) insect treatment in which holes were drilled into the top $20 \%$ of the trunks to mimic wood-boring insect attack; (a) day 1 of cutoff treatment (aerial view); (b) final day of cutoff treatment with viscous white resin visible; (c) day 1 of the insect treatment with one drilled hole and initial resin exudation visible (arrowhead); (d) final day of insect treatment in which three drill holes have exuded less viscous white resin (arrowheads). 

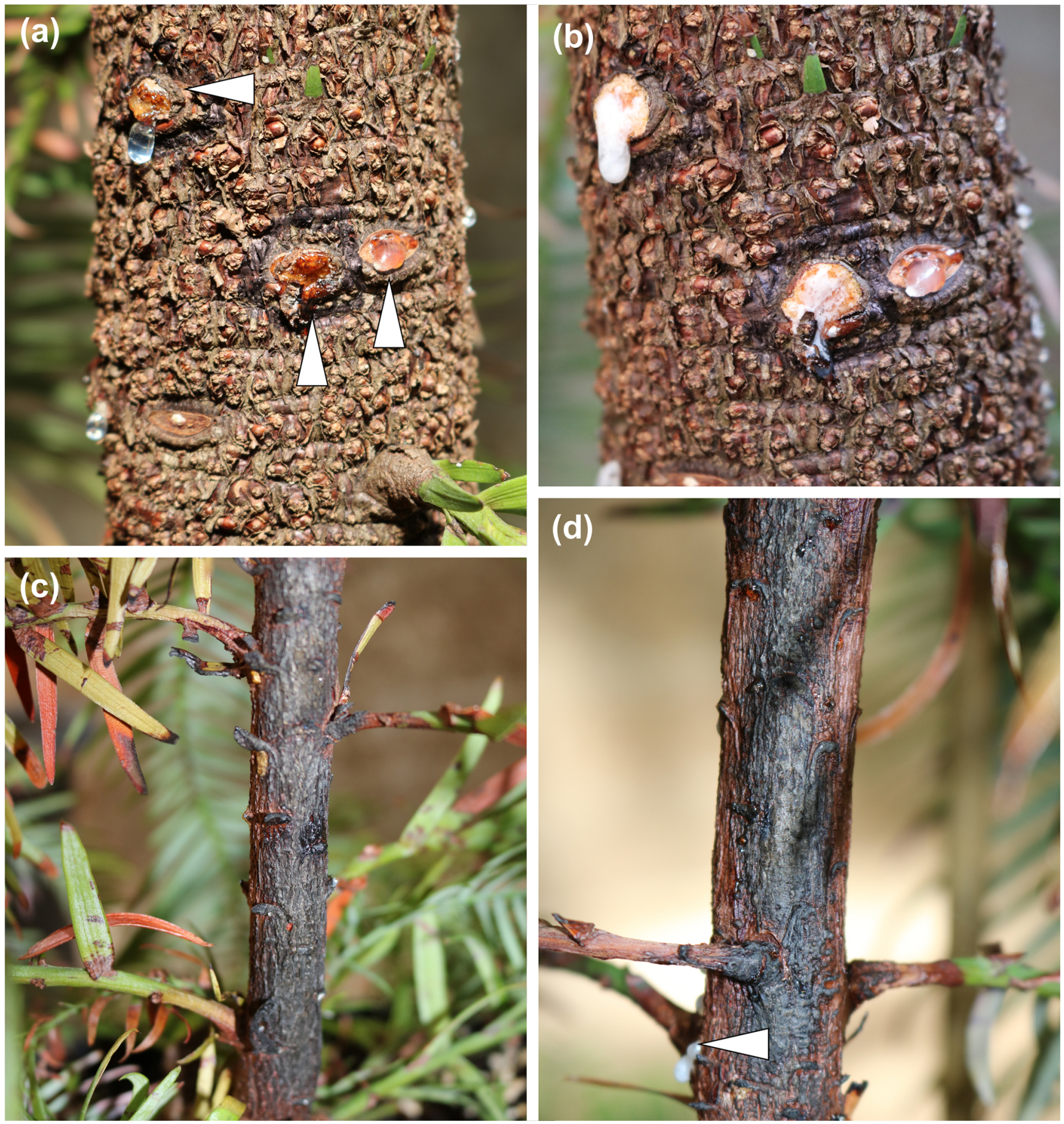

Figure 6. Experimental Wollemia nobilis examples: (a-b) branch treatment in which three upper branches were removed to mimic noncatastrophic damage; (c-d) burn treatment in which each tree was burned on one side creating a burn $6 \mathrm{~cm}$ in length along the trunk to mimic a wild fire burning at a low level; (a) day 1 of branch treatment with three cuts (arrowheads); (b) final day of branch treatment (same tree as a with small amounts of viscous resin visible at each cut site); (c) day 1 of the burn treatment with no apparent resin exuded; (d) final day of burn treatment with minimal resin exudation (arrowhead). 

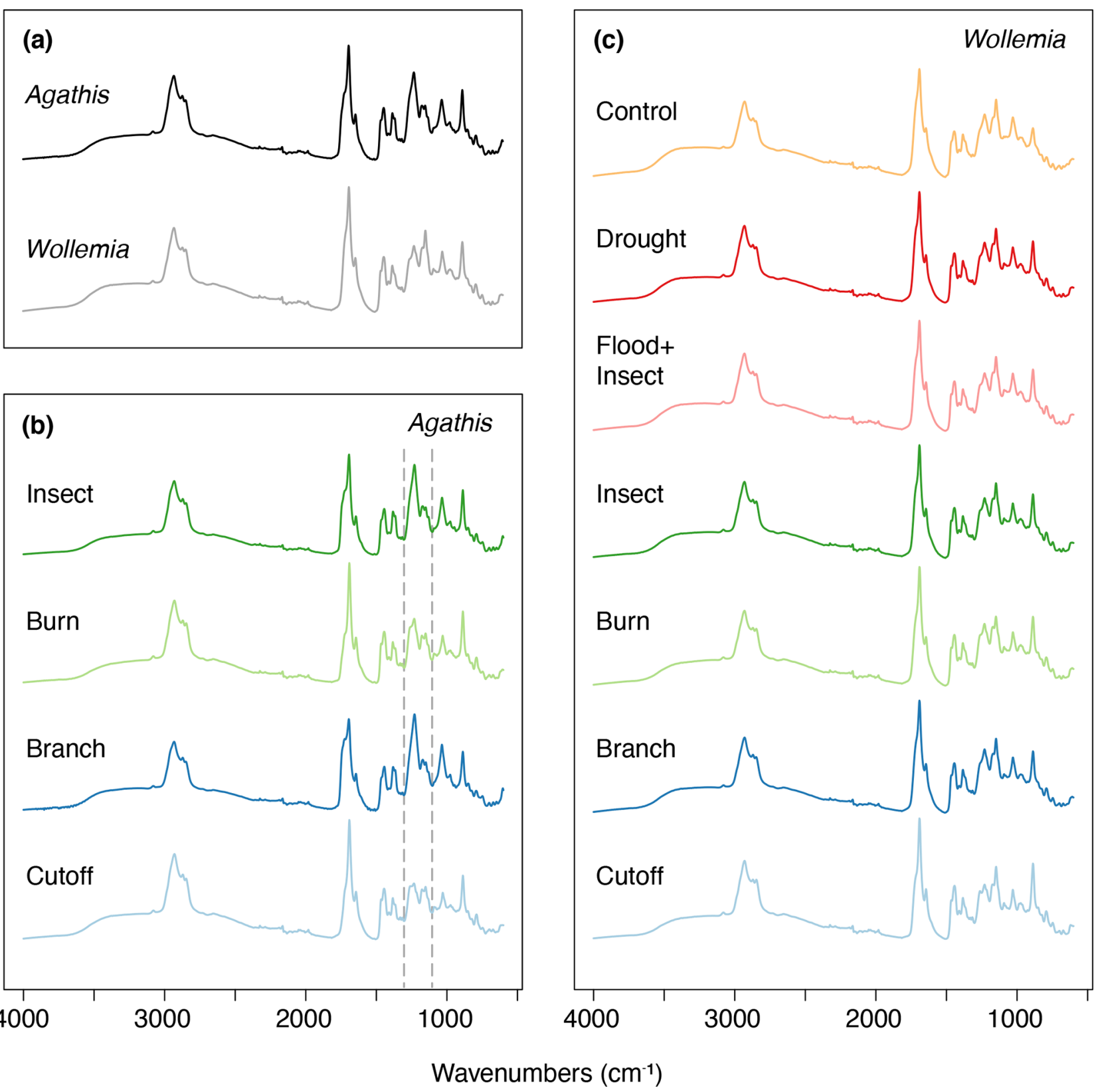

Figure 7. Mean FTIR-ATR spectra for (a) Agathis and Wollemia; (b) the four effective Agathis treatments, the dashed lines indicating the area of key differences between the mean spectra; (c) the six effective Wollemia treatments plus the control group.

\subsection{Wollemia resin exudation experiment}

Very little resin was exuded by all trees across the experiment. The control trees were found, as expected, to produce no resin during the observation period, although the resinous polar cap was collected for testing, becoming the "control" samples. The flood-treated plants produced the least resin of the other treatments, so little that there was not enough for testing. The next lowest amounts of resin were obtained from the drought and flood + insect treatments, although there was just enough resin for testing collected. The cutoff (Fig. 5b) and branch (Fig. 6b) treatments provided more resin, and the most resin was collected from the insect (Fig. 5d) and burn (Fig. 6d) treatments. In terms of viscosity the pattern was similar to the Agathis experiments in that the most viscous resins were exuded in response to the cutoff and all burn treatments (Figs. 5b, 6d). Also, some of the insect and branch treatment trees yielded the least viscous resins (Figs. 5d, 6d) but again not all and not at every injury site on the same tree. The two treatments for which there was more than one sampled resin per tree (branch and insect) also showed spectral variation within one tree, suggesting that the height of the 
(a)

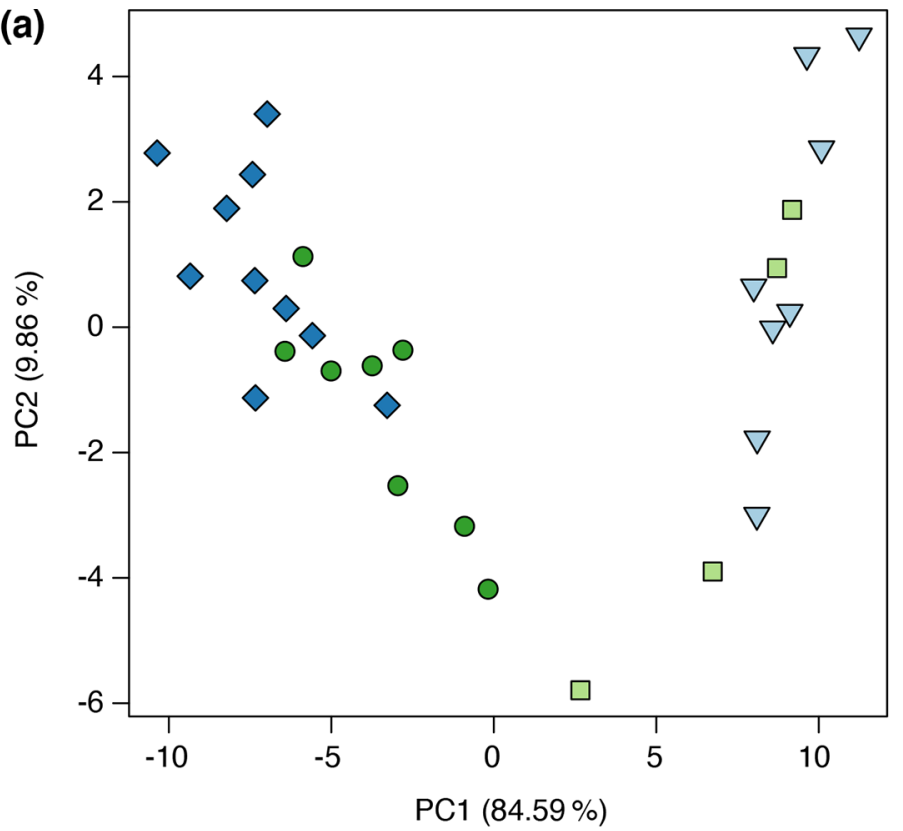

(b)

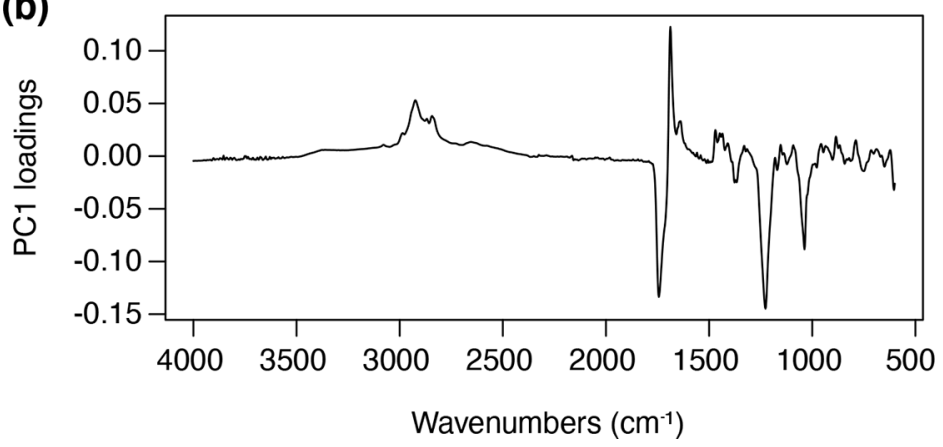

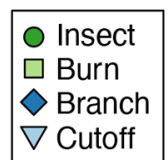

$\checkmark$ Cutoff

(c)

- Insect

Insect

Insect

Insect

Branch

Insect

Branch

Branch

Branch

Branch

Insect

Branch

Branch

Branch

Branch

Branch

Insect

Insect

Burn

Burn
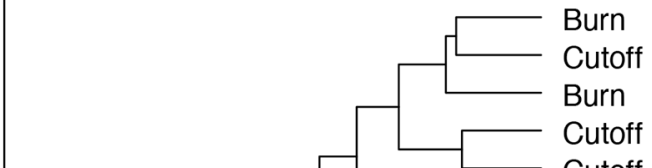

Cutoff

- Cutoff

- Cutoff

- Cutoff

- Burn

- Cutoff

- Cutoff

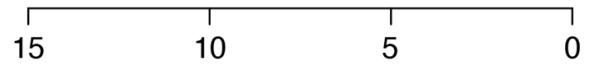

Euclidean distance

Figure 8. Multivariate analysis of Agathis resin spectra using FTIR-ATR spectroscopy: (a) principal component analysis showing PC1 vs. PC2; (b) loadings for PC1; (c) cluster analysis.

treatment placement was also a minor factor in the variation (Fig. 9a). Only two from four of the branch treatment resin spectra are overlapping and so are very similar. These derive from the same tree; however, the third from this tree does not group with these two spectra. Additionally, the resin spectrum from a different tree with the same branch treatment does not closely group with any of these other branch treatment spectra. A similar pattern is also noted in the insect treatment spectra in which samples from the same tree show a large amount of variance (Fig. 9a).

The Wollemia mean spectrum is broadly similar to that of Agathis and especially those mean resin spectra recovered from the Agathis burn and cutoff treatments (Fig. 7a). This suggests that the chemical bonds and therefore components of the resins are similar but not completely identical. In Agathis resin mean spectra, the peak at $1229 \mathrm{~cm}^{-1}$ is higher than those found at 1174 and $1150 \mathrm{~cm}^{-1}$. In Wollemia, this peak intensity pattern is reversed (Fig. 7). Overall, the mean spectra per treatment (Fig. 7c) are broadly similar in the
Wollemia experiment with limited evidence for differences tied to treatment type.

For the Wollemia experiment, $82.5 \%$ of the variance was explained by two principal components (percentage of variance for PC1: $63.50 \%$; PC2: $19.03 \%$; standard deviation for PC1: 3.04; PC2: 1.66). The PCA (Fig. 9a) shows some within-treatment groupings, but there is a lot of overlap. The variation across the treatments and samples of the Wollemia trees is also far smaller than that observed with the Agathis ones. The potentially oldest resins (from the polar cap of the controls, $n=2$ ) cluster together on PC1 perhaps due to their age (and so degree of polymerisation) and/or position on the trees. An additional possibility is that the polar caps are more degraded than the other resin found as droplets as the cap resin layers are very thin, perhaps linked to the way they drop off in scales when the tree starts growing. The PC1 loadings for Wollemia show that the wide peak found around $3400 \mathrm{~cm}^{-1}$ and the peaks at 1693 and $887 \mathrm{~cm}^{-1}$, identified above, are key to the minor spectral differences in the 

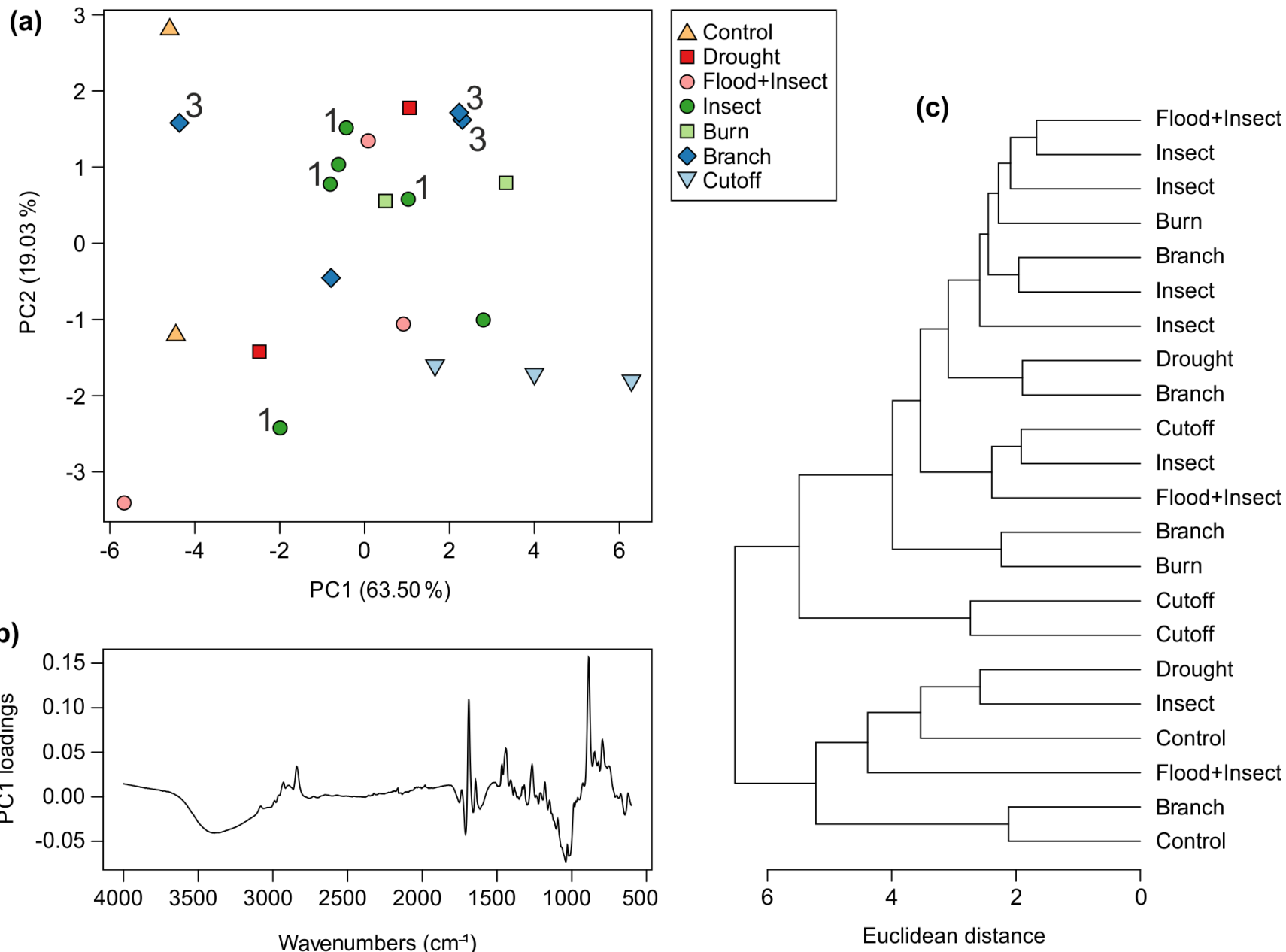

(b)

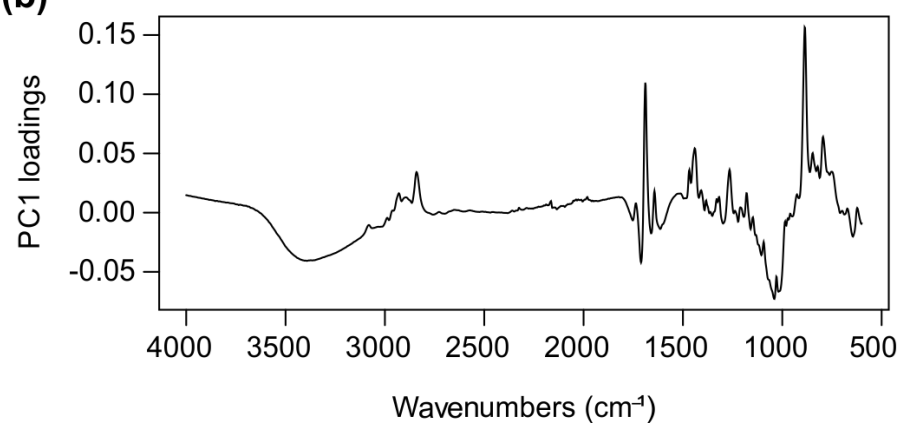

Figure 9. Multivariate analysis of Wollemia resin spectra using FTIR-ATR spectroscopy: (a) principal component analysis showing PC1 vs. PC2 - 3 indicates the three branch samples that came from different heights on the same tree (tree 3), and 1 indicates the four insect samples that came from different heights on the same tree (tree 1); (b) loadings for PC1; (c) cluster analysis.

Wollemia treatments (Fig. 9b). The cluster analysis (Fig. 9c) also shows no clear-cut patterns or groupings based around treatment.

\subsection{Combined analysis of the resin exudation experiments}

In a combined analysis of both datasets $86.4 \%$ of the variance was accounted for by two principal components (proportion of variance for PC1: $68.20 \%$; PC2: $18.19 \%$; standard deviation for PC1: 6.56; PC2; 3.39). The PCA (Fig. 10a) and cluster analysis (Fig. 10c) show that, across the resin dataset, there is a distinction between two of the Agathis treatments (insect and branch) that group together, as well as the remaining Agathis treatments and all the Wollemia treatment resins that grade together. However, the Wollemia spectra group more closely to each other than the remaining Agathis resins, which is consistent with there being far less variation in these spectra compared to those of Agathis. The
PC1 loadings for the combined treatment PCA (Fig. 10b) are broadly similar to those in the Agathis experiment (Fig. 8b), albeit with the positive and negative loadings inverted (i.e. the chemical gradient runs in the opposite direction along PC1).

\section{Discussion}

One key observation is that there is variation seen between the resin spectra for the same treatment, i.e. there is variation between the replicates for each treatment (see Figs. 8a and $9 \mathrm{a}$ ). This variation is noted for both genera, i.e. in the seed-grown (and so more genetically varied) Agathis trees and in the almost genetically identical Wollemia trees. Additionally, in the Wollemia experiment, there were two treatments (branch and insect) with more than one sample from an individual tree. This allowed us to test the effects of the same treatments at different heights on the trees and to ob- 

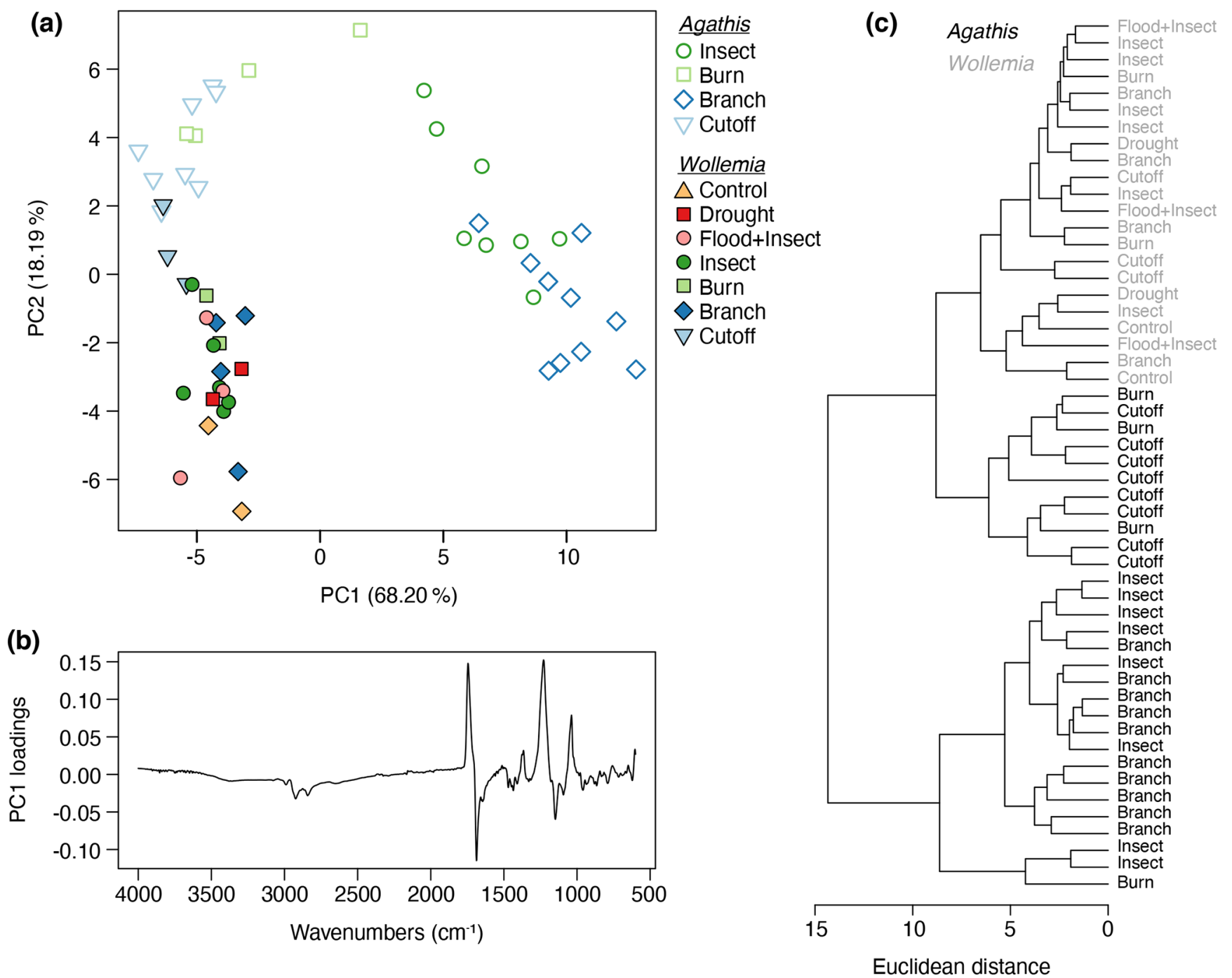

Figure 10. Agathis and Wollemia resin spectra from FTIR-ATR spectroscopy analysed together: (a) principal component analysis showing PC1 vs. PC2 - open symbols indicate Agathis-derived resins, closed symbols indicate Wollemia-derived resins, and the different coloured treatments are the same as in Figs. 8a and 9a; (b) loadings for PC1; (c) cluster analysis.

serve the resultant resin spectral variation (Fig. 9a). These Wollemia results show that even within one tree, the same treatment can yield resins with differing spectra.

The fact that the Agathis branch- and insect-derived resin spectra are more different from the others (Figs. 7 and 8) seems to tally with the observations during the experiment that these resins (plus the one Agathis burn treatment that groups nearer these two; Fig. 8) were on average far less viscous resins - the resins flowed further from their points of origin than in the other Agathis treatments (compare Figs. 2b, $\mathrm{d}, 3 \mathrm{~b}$ and d). When just considering the Agathis spectra, this reaction may be linked to the differences in the placement of the damage on the experimental trees. The branch and insect treatments were mostly towards the upper parts of the trees, whereas the burn and cutoff damage was inflicted lower on the trunks $(20 \mathrm{~cm}$ from the base for the cutoff and $20-30 \mathrm{~cm}$ from the base for the burn to one side of the trunk). It may also be linked to the severity of the damage inflicted on the trees. More severe or a larger area of damage was inflicted on the burn and cutoff trees (Figs. 2a-b, 3a-b), and the insect and branch were more spot-based damage, causing smaller and perhaps not so deep areas of damage in total (Figs. 2c-d, $3 \mathrm{c}-\mathrm{d})$.

The key difference in the peaks present in the Agathis branch- and insect-derived resin spectra compared to the others is the larger peak at $1229 \mathrm{~cm}^{-1}$ that is followed by a smaller doublet at 1174 and $1150 \mathrm{~cm}^{-1}$ (Figs. 7b, 8b). The peaks at 1174 and $1150 \mathrm{~cm}^{-1}$ are due to $\mathrm{C}-\mathrm{O}$ single bonds, but how they affect resin viscosity is not known. Tappert et al. (2011) noted that as the wide peak at around $3400 \mathrm{~cm}^{-1}$ attributed to hydroxyl content increases, the intensity of some peaks including that at $1229 \mathrm{~cm}^{-1}$ is also af- 
fected. They linked the $3400 \mathrm{~cm}^{-1}$ peak to the level of polymerisation in the resin, but they could not find a reason for this relationship with the other peaks such as at $1229 \mathrm{~cm}^{-1}$. As the intensity of the $3400 \mathrm{~cm}^{-1}$ peak in the Agathis spectra is unchanging, suggesting a similar lack of polymerisation across the Agathis resins, it is unclear what the underlying reason could be for the relative strength of the peak at $1229 \mathrm{~cm}^{-1}$ and how it influences viscosity.

However, there were less viscous Wollemia resins noted (particularly for some of the insect treatments; Fig. 5d), and no Wollemia-derived resin spectra grouped with the more distinct branch- and insect-derived resin spectra, instead forming more of a grade with the remaining Agathis burn- and cutoff-derived resin spectra (Fig. 10). Additionally, the scale of the damage was comparable to that in the Agathis trees, but no clear separation of the treatments was seen in Wollemia resin spectra (Fig. 9), suggesting that the variation in the resin chemistry is not strongly tied to specific treatments for Wollemia.

In the Wollemia experiment we observed that the insect treatment yielded ample resins for sampling from two of the three trees, whereas the flood treatment resulted in only trace amounts of resin and so are not included in the analyses here. The combined flood + insect treatment did yield some resin, but a far smaller amount of resin than that recovered from the insect treatment. The effect of this double treatment in possibly suppressing the resin amount may be explained by the fact that the flood effect severely affected the treatment trees, killing some in both the single flood and the double flood + insect treatments. We suggest the strength of this flood stress in either of those treatments was so great, perhaps by causing anoxia to the roots for a prolonged period, that the treatment trees could likely only maintain their basic physiological needs and could not afford the extra investment for producing secondary substances, The flood treatment, either alone or in combination with the insect treatment, appears to be a severe event that likely disturbed and limited the physiological activities of the trees. The full effects of different types of flood treatments on resin production should be tested in future experiments.

The resins derived from the Agathis experiments are far more variable in their spectra and hence chemistry than those derived from the Wollemia experiment, and this is particularly clear when looking at the combined dataset (Fig. 10). The stand-out difference in resin spectra are the Agathis branch and insect treatments (Figs. 7 and 8) which group together but away from the other treatments and species' spectra (Fig. 10). The most important difference in the spectra from these two (Agathis) treatments is seen in the mean spectra, in which there is a more intense single peak at $1229 \mathrm{~cm}^{-1}$ compared to the less intense shouldered peak observed for the Agathis burn and cutoff treatments (Fig. 7b). The mean Wollemia spectra also lacked this intense peak and have instead the less intense shouldered peak (Fig. 7c), explaining at least in part why these Agathis branch- and insect- derived resin spectra do not group with the other resin spectra (Fig. 10). The Wollemia-derived resin spectra did show some overlapping grouping according to treatment (Figs. 9 and 10), but there was no notable single peak, just slight variations in different peak intensities in the fingerprint region (Fig. 7c). However, the loadings for PC1 (Fig. 9b) show that the limited variation is dominated by a few key peaks ( 3400 , 1693 , and $887 \mathrm{~cm}^{-1}$ ), with that at around $3400 \mathrm{~cm}^{-1}$ indicating small differences in the level of polymerisation between the resins. Small differences in the $\mathrm{C}-\mathrm{O}$ double bonds in carboxyl groups of resin acids $\left(1693 \mathrm{~cm}^{-1}\right)$ and out-of-plane C$\mathrm{H}$ bending motions in terminal methylene groups $\left(887 \mathrm{~cm}^{-1}\right)$ were also highlighted, but these cannot be directly linked to any treatment (Fig. 9).

The low variability in Wollemia-derived resin spectra may be a result of having so few trees in the experiment and of its extremely low genetic variation as the trees were all clonally derived from a very inbred wild population with almost no genetic variation reported (Peakall et al., 2003; Greenfield et al., 2016). Trying to understand the potential genetic contribution to resin variability was a key idea to test here and the reason for selecting clonal Wollemia for the experiment. In contrast, the seed-grown Agathis trees likely reflect far more natural genetic variability, and this may affect their resin chemical diversity to some degree.

These are the first results on resin chemistry that suggest that the genetic variability of the resinous plants should also be considered when examining resin (and hence amber in the fossil record). The extremely low amounts of Wollemia resins exuded were surprising. It may be that Wollemia is just not as resinous as A. australis, or that, as these plants were grown away from their natural occurrence in Australia, they were less suited to producing more resin unlike the A. australis trees grown in their natural range, or that these clones were taken from less resinous plants in the wild population.

Interestingly, Agathis and Wollemia clustered separately in the combined experiment analysis, although this was secondary to the grouping of the Agathis branch- and insectderived spectra vs. the rest of the dataset (Fig. 10). Nevertheless, this suggests that taxonomic signatures may be maintained in resins despite variations in stimulus type, which is encouraging from the point of view of chemotaxonomy of resins and ambers. This means that the use of FTIR spectroscopy for determining the likely botanical source of an amber, such as by Tappert et al. (2011) and Seyfullah et al. (2015), is still valid.

From this work, we cannot show clear differences in the Araucariacean resins tested that link to a particular resininducing treatment. This means, unfortunately, that within these conifer-derived resins, we are not able to consistently detect the presence of chemical differences linked to a treatment using just FTIR. There may be unusual secondary metabolites included in the resin, such as those detected in different angiosperm-derived ambers by McCoy et al. (2017b) and Dutta et al. (2017), but which are unde- 
tectable using FTIR alone. Whether these are also present in gymnosperm-derived ambers is not yet known. What is clear is that the use of testing on extant plants is vital to show how plants actually react to stimuli, and this is important as it highlights the need for care in interpreting what signals may be stored in amber. The natural resin variability measured here means that caution is needed when interpreting data from amber as multiple samples should be tested and averaged when possible.

\section{Conclusions}

Resin production in Agathis australis was greater than in Wollemia nobilis for the same test stimuli. Different stimuli tested for resin exudation did not give clearly distinguishable signatures using FTIR, especially for the Wollemia-derived resins. In Agathis two groupings were distinguishable, which appear linked with resin viscosity and severity of the damage inflicted on the test trees from different treatments, although no clear chemical signal could be interpreted. However, with FTIR the two different species could be distinguished no matter the treatment. The effect of genetic variation was also considered using the same stimuli on both the seed-grown Agathis australis derived from wild-collected populations in northern New Zealand and on clonally derived Wollemia nobilis plants with natural minimal genetic diversity. The resins did reflect the genetic variability in their resin chemistry, with the Agathis resins showing far greater resin chemistry variation than those of Wollemia in response to the same stimulus. We suggest that this natural variability needs to be taken into account when testing, reporting, and comparing resin and amber chemistries in the future.

Code and data availability. All datasets and R code are included in the Supplement.

Supplement. The supplement related to this article is available online at: https://doi.org/10.5194/fr-24-321-2021-supplement.

Author contributions. LJS designed the project. LJS and ARS set up the Wollemia experiments. LJS performed the experiments, collected samples, and prepared and ran the FTIR analyses. LJS, EAR, and PEJ undertook the statistical analyses based on R code adapted from PEJ. All authors worked on the draft, reviewed the final version of the paper, and approved it.

Competing interests. Some authors are members of the editorial board of Fossil Record. The peer-review process was guided by an independent editor, and the authors have also no other competing interests to declare.
Disclaimer. Publisher's note: Copernicus Publications remains neutral with regard to jurisdictional claims in published maps and institutional affiliations.

Acknowledgements. We warmly thank all the extremely knowledgeable and incredibly kind staff at Oratia Plant Nursery, New Zealand, and in particular the owner Geoff Davidson for his generosity in growing the Agathis trees for so long and allowing the experiment to take place on site and without whom this project would not have succeeded. We also warmly thank the curator and gardeners of the Experimental Botanical Garden of the University of Göttingen, especially Regina Helbig and Lars Köhler for their expertise and care of the Wollemia trees through the years of the project. We also very kindly thank Burkhard C. Schmidt for generously supporting access and extensive help with the FTIR-ATR at the Department of Mineralogy, University of Göttingen. We also thank Eugenio Ragazzi and one other reviewer for their very helpful and supportive comments.

Financial support. This project was funded by the German Research Foundation through project 313947174 (SE2335/3-1) to Leyla J. Seyfullah. Phillip E. Jardine is currently funded via DFG project 443701866 .

Review statement. This paper was edited by Florian Witzmann and reviewed by Eugenio Ragazzi and one anonymous referee.

\section{References}

Aquilina, L., Girard, V., Hénin, O., Bouhnik-Le Coz, M., Vilbert, D., Perrichot, V., and Néraudeau, D.: Amber inorganic geochemistry: new insight into the environmental processes in a Cretaceous forest of France, Palaeogeogr. Palaeocl., 369, 220-227, https://doi.org/10.1016/j.palaeo.2012.10.023, 2013.

Beltran, V., Salvadó, N., Butí, S., and Pradell, T.: Ageing of resin from Pinus species assessed by infrared spectroscopy, Anal. Bioanal. Chem., 408, 4073-4082, https://doi.org/10.1007/s00216-016-9496-x, 2016.

Dal Corso, J., Roghi, G., Ragazzi, E., Angelini, I., Giaretta, A., Soriano, C., Delclòs, X., and Jenkyns, H. C.: Physico-chemical analysis of Albian (Lower Cretaceous) amber from San Just (Spain): implications for palaeoenvironmental and palaeoecological studies, Geol. Acta, 11, 359-370, https://doi.org/10.1344/105.000001871, 2013.

Dal Corso, J., Schmidt, A. R., Seyfullah, L. J., Preto, N., Ragazzi, E., Jenkyns, H. C., Delclòs, X., Néraudeau, D., and Roghi, G.: Evaluating the use of amber in palaeoatmospheric reconstructions: the carbon-isotope variability of modern and Cretaceous conifer resins, Geochim. Cosmochim. Ac. 199, 351-369, https://doi.org/10.1016/j.gca.2016.11.025, 2017.

Dutta, S., Mehrotra, R. C., Paul, S., Tiwari, R. P., Bhattacharya, S., Srivastava, G., Ralte, V. Z., and Zoramthara, C.: Remarkable preservation of terpenoids and record of volatile signalling in plant-animal interactions from Miocene amber, Sci. Rep.-UK, 7, 10940, https://doi.org/10.1038/s41598-017-09385-w, 2017. 
Gaigalas, A. and Halas, S.: Stable isotopes (H, C, S) and the origin of Baltic amber, Geochronometria, 33, 33-36, https://doi.org/10.2478/v10003-009-0001-9, 2009.

Greenfield, A., McPherson, H., Auld, T., Delaney, S., Offord, C., van der Merwe, M., Yap, S. and Rossetto. M.: Wholechloroplast analysis as an approach for fine-tuning the preservation of a highly charismatic but critically endangered species, Wollemia nobilis (Araucariaceae), Aust. J. Bot., 64, 654-658, https://doi.org/10.1071/BT16105, 2016.

Grimaldi, D.: Amber: Window to the Past, Harry N. Abrams, Incorporated, New York, 1996.

Grimaldi, D., Bonwich, E., Delannoy, M., and Doberstein, S.: Electron microscopic studies of mummified tissues in amber fossils, Am. Mus. Novit., 3097, 1-31, 1994.

Grimaldi, D., Shedrinsky, A., and Wampler, T. P.: A remarkable deposit of fossiliferous amber from the Upper Cretaceous (Turonian) of New Jersey, in: Studies on Fossils in Amber, with Particular Reference to the Cretaceous of New Jersey, edited by: Grimaldi, D., Backhuys Publishing, Leiden, 1-76, 2000.

Henwood, A.: Exceptional preservation of dipteran flight muscle and the taphonomy of insects in amber, PALAIOS, 7, 203-12, 1992.

Lambert, J. B., Johnson, S. C., Poinar Jr., G. O., and Frye, J. S.: Recent and fossil resins from New Zealand and Australia, Geoarchaeology, 8, 141-155, 1993.

Langenheim, J. H.: Plant resins, Am. Sci., 78, 16-24, 1990.

Liland, K. H., Almøy, T., and Mevik, B.-H.: Optimal Choice of Baseline Correction for Multivariate Calibration of Spectra, Appl. Spectr., 64, 1007-1016, 2010.

Lyons, P. C., Masterlerz, M., and Orem, W. H.: Organic geochemistry of resins from modern Agathis australis and Eocene resins from New Zealand: diagenetic and taxonomic implications, Int. J. Coal Geol., 80, 51-62, https://doi.org/10.1016/j.coal.2009.07.015, 2009.

McCoy, V. E., Soriano, C., and Gabbott, S. G.: A review of preservational variation of fossil inclusions in amber of different chemical groups, Earth Env. Sci. T. R. So., 107, 203-211, https://doi.org/10.1017/S1755691017000391, 2017a.

McCoy, V. E., Boom, A., Solórzano Kraemer, M. M., and Gabbott, S. E.: The chemistry of American and African amber, copal, and resin from the genus Hymenaea, Org. Geochem., 113, 43-54, https://doi.org/10.1016/j.orggeochem.2017.08.005, 2017b.

McCoy, V. E., Gabbott, S. E., Penkman, K., Collins, M. J., Presslee, S., Holt, J., Grossman, H., Wang, B., Solórzano Kraemer, M. M., Delclòs, X., and Peñalver, E.: Ancient amino acids from fossil feathers in amber, Sci. Rep.-UK, 9, 6420, https://doi.org/10.1038/s41598-019-42938-9, 2019.

McKellar, R. C., Wolfe, A. P., Muehlenbachs, K., Tappert, R., Engel, M. S., Cheng, T., and Sánchez-Azofeifa, G. A.: Insect outbreaks produce distinctive carbon isotope signatures in defensive resins and fossiliferous ambers, P. R. Soc. B., 278, 3219-3224, https://doi.org/10.1098/rspb.2011.0276, 2011.

Najarro, M., Penãlver, E., Pérez-de la Fuente, R., Ortega-Blanco, J., Menor-Salván, C., Barrón, E., Soriano, C., Rosales, I., López del Valle, R., Velasco, F., Tornos, F., Daviero-Gomez, V., Gomez, B., and Delclòs, X.: Review of the El Soplao amber outcrop, Early Cretaceous of Cantabria, Spain, Acta Geol. Sin.-Engl., 84, 959976, 2010.
Neuwirth, E.: RColorBrewer: ColorBrewer Palettes, R package version 1.1-2, available at: https://CRAN.R-project.org/package= RColorBrewer (last access: 1 May 2021), 2014.

Nissenbaum, A. and Yaker, D.: Stable isotope composition of amber, in: Amber, resinite and fossil resins, edited by: Anderson, K. B. and Crelling, J. C., ACS Symposium Series, 617, 32-42, American Chemical Society, Washington DC, 1995.

Nissenbaum, A., Yakir, D., and Langenheim, J. H.: Bulk carbon, oxygen, and hydrogen stable isotope composition of recent resins from amber producing Hymenaea, Naturwissenschaften, 92, 2629, 2005.

Otto, A., Simoneit, B. R. T., Wilde, V., Kunzmann, L., and Püttmann, W.: Terpenoid composition of three fossil resin from Cretaceous and Tertiary conifers, Rev. Palaeobot. Palyno., 120, 203-215, https://doi.org/10.1016/S0034-6667(02)00072-6, 2002.

Peakall, R., Ebert, D., Scott, L. J., Meagher, P. F., and Offord, C. A.: Comparative genetic study confirms exceptionally low genetic variation in the ancient and endangered relictual conifer, Wollemia nobilis (Araucariaceae), Mol. Ecol., 12, 2331-2343, https://doi.org/10.1046/j.1365-294x.2003.01926.x, 2003.

Pereira, R., de Souza Carvalho, I., Simoneit, B. R. T., and de Almeida Azevedo, D.: Molecular composition and chemisystematic aspects of Cretaceous amber from Amazonas, Araripe and Recôncavo basins, Brazil, Org. Geochem., 40, 863-875, https://doi.org/10.1016/j.orggeochem.2009.05.002, 2009.

Ragazzi, E. and Schmidt, A. R.: Amber, in: Encyclopedia of Geobiology, edited by: Reitner, J. and Thiel, V., Springer, Dordrecht, 24-36, 2011.

R Core Team: R: A language and environment for statistical computing. R Foundation for Statistical Computing, Vienna, Austria, available at: https://www.R-project.org/, last access: 1 May 2021.

Rust, J., Singh, H., Rana, R. S., McCanna, T., Singh, L., Anderson, K., Sarkare, N., Nascimbene, P. C., Stebner, F., Thomas, J. C., Solórzano Kraemer, M., Williams, C. J., Engel, M. S., Sahni, A., and Grimaldi, D.: Biogeographic and evolutionary implications of a diverse paleobiota in amber from the early Eocene of India, P. Natl. Acad. Sci. USA, 107, 18360-18365, https://doi.org/10.1073/pnas.1007407107, 2010.

Schmidt, A. R., Kaulfuss, U., Bannister, J. M., Baranov, V., Beimforde, C., Bleile, N., Borkent, A., Busch, A., Conran, J. G., Engel, M. S., Harvey, M., Kennedy, E. M., Kerr, P., Kettunen, E., Kiecksee, A. P., Lengeling, F., Lindqvist, J. K., Maraun, M., Mildenhall, D. C., Perrichot, V., Rikkinen, J., Sadowski, E.-M., Seyfullah, L. J., Stebner, F., Szwedo, J., Ulbrich, P., and Lee, D. E.: Amber inclusions from New Zealand, Gondwana Res., 56, 135-146, https://doi.org/10.1016/j.gr.2017.12.003, 2018.

Seyfullah, L. J., Sadowski, E. M., and Schmidt, A. R.: Species-level determination of closely related araucarian resins using FTIR spectroscopy and its implications for the provenance of New Zealand amber, PeerJ, 3, e1067, https://doi.org/10.7717/peerj.1067, 2015.

Seyfullah, L. J., Beimforde, C., Dal Corso, J., Perrichot, V., Rikkinen, J., and Schmidt, A. R.: Production and preservation of resins - past and present, Biol. Rev., 93, 1684-1714, https://doi.org/10.1111/brv.12414, 2018a.

Seyfullah, L. J., Roghi, G., Dal Corso, J., and Schmidt, A. R.: The Carnian Pluvial Episode and the first global ap- 
pearance of amber, J. Geol. Soc. Lond., 175, 986-988, https://doi.org/10.1144/jgs2017-143, 2018b.

Steward, G. A. and Beveridge, A. E.: A review of New Zealand kauri (Agathis australis (D.Don) Lindl.): its ecology, history, growth and potential for management for timber, NZ, J. Forest. Sci., 40, 33-59, 2010.

Stout, S. A.: Resin-derived hydrocarbons in fresh and fossil Dammar resins and Miocene rocks and oils in the Mahakam delta, Indonesia, in: Amber, Resinite and Fossil Resins, edited by: Anderson, K. B. and Crelling, J. C., American Chemical Society, Washington D.C., 43-75, 1995.

Tappert, R., Wolfe, A. P., McKellar, R. C., Tappert, C. M., and Muehlenbachs, K.: Characterizing modern and fossil conifer exudates using micro-FTIR spectroscopy, Int. J. Plant Sci., 172, 120-138, https://doi.org/10.1086/657277, 2011.

Thomas, D. B., Nascimbene, P. C., Dove, C. J., Grimaldi, D. A., and James, H. F.: Seeking carotenoid pigments in amber-preserved fossil feathers, Sci. Rep.-UK, 4, 1-6, https://doi.org/10.1038/srep05226, 2014.
Varmuza, K. and Filzmoser, P.: Introduction to multivariate statistical analysis in chemometrics, CRC Press (Taylor \& Francis) Boca Raton, FL, USA, 2009.

Wolfe, A. P., McKellar, R. C., Tappert, R., Sodhi, R. N. S., and Muehlenbachs, K.: Bitterfeld amber is not Baltic amber: Three geochemical tests and further constraints on the botanical affinities of succinite, Rev. Palaeobot. Palyno., 225, 21-32, https://doi.org/10.1016/j.revpalbo.2015.11.002, 2016.

Yamamoto, S., Otto, A., Krumbiegel, G., and Simoneit, B. R. T.: The natural product biomarkers in succinite, glessite and stantienite ambers from Bitterfeld, Germany, Rev. Palaeobot. Palyno., 140, 27-49, https://doi.org/10.1016/j.revpalbo.2006.02.002, 2006. 